\title{
Pathogenic implications of cerebrospinal fluid barrier pathology in neuromyelitis optica
}

\author{
Yong Guo $^{1} \cdot$ Stephen D. Weigand $^{2} \cdot$ Bogdan F. Popescu $^{3} \cdot$ Vanda A. Lennon $^{1,4,5,6} \cdot$ Joseph E. Parisi $^{1,4}$ \\ Sean J. Pittock ${ }^{1,6}$ - Natalie E. Parks ${ }^{1} \cdot$ Stacey L. Clardy $^{1}$ Charles L. Howe ${ }^{1,5,6,7}$ - Claudia F. Lucchinetti ${ }^{1,6}$
}

Received: 6 August 2016 / Revised: 12 January 2017 / Accepted: 25 January 2017 / Published online: 9 February 2017

(C) The Author(s) 2017. This article is published with open access at Springerlink.com

\begin{abstract}
Pathogenic autoantibodies associated with neuromyelitis optica (NMO) induce disease by targeting aquaporin-4 (AQP4) water channels enriched on astrocytic endfeet at blood-brain interfaces. AQP4 is also expressed at cerebrospinal fluid (CSF)-brain interfaces, such as the pial glia limitans and the ependyma and at the choroid plexus blood-CSF barrier. However, little is known regarding pathology at these sites in NMO. Therefore, we evaluated AQP4 expression, microglial reactivity, and complement deposition at pial and ependymal surfaces and in the fourth ventricle choroid plexus in 23 autopsy cases with clinically
\end{abstract}

Electronic supplementary material The online version of this article (doi:10.1007/s00401-017-1682-1) contains supplementary material, which is available to authorized users.

\section{Charles L. Howe}

howe@mayo.edu

$\triangle$ Claudia F. Lucchinetti

clucchinetti@mayo.edu

1 Department of Neurology, Mayo Clinic, 200 First Street SW, Rochester, MN 55905, USA

2 Department of Health Sciences Research, Mayo Clinic, Rochester, MN, USA

3 Department of Anatomy and Cell Biology, Cameco MS Neuroscience Research Center, University of Saskatchewan, Saskatoon, SK, Canada

4 Department of Laboratory Medicine and Pathology, Mayo Clinic, Rochester, MN, USA

5 Department of Immunology, Mayo Clinic, Rochester, MN, USA

6 Center for Multiple Sclerosis and Autoimmune Neurology, Mayo Clinic, Rochester, MN, USA

7 Department of Neuroscience, Mayo Clinic, Rochester, MN, USA and/or pathologically confirmed NMO or NMO spectrum disorder. These findings were compared to five cases with multiple sclerosis, five cases of choroid plexus papilloma, and five control cases without central nervous system disease. In the NMO cases, AQP4 immunoreactivity was reduced relative to control levels in the pia $(91 \% ; 21 / 23)$, ependyma $(56 \%$; 9/16), and choroid plexus epithelium $(100 \% ; 12 / 12)$. AQP4 immunoreactivity was normal in MS cases in these regions. Compared to MS, NMO cases also showed a focal pattern of pial and ependymal complement deposition and more pronounced microglial reactivity. In addition, AQP4 loss, microglial reactivity, and complement deposition colocalized along the pia and ependyma only in NMO cases. Within the choroid plexus, AQP4 loss was coincident with C9neo immunoreactivity on epithelial cell membranes only in NMO cases. These observations demonstrate that NMO immunopathology extends beyond perivascular astrocytic foot processes to include the pia, ependyma, and choroid plexus, suggesting that NMO IgG-induced pathological alterations at CSF-brain and blood-CSF interfaces may contribute to the occurrence of ventriculitis, leptomeningitis, and hydrocephalus observed among NMO patients. Moreover, disruption of the blood-CSF barrier induced by binding of NMO IgG to AQP4 on the basolateral surface of choroid plexus epithelial cells may provide a unique portal for entry of the pathogenic antibody into the central nervous system.

Keywords Choroid plexus - Leptomeninges - Astrocyte · Complement · Immunopathology $\cdot$ Hydrocephalus

\section{Introduction}

Neuromyelitis optica (NMO) is a disabling inflammatory disorder of the central nervous system (CNS) that is marked 
by expression of a pathogenic IgG autoantibody directed against the ectodomain of aquaporin-4 (AQP4), the major water channel in the CNS $[34,35]$. AQP4 functions to couple bidirectional fast water transport to active ion flux across the plasma membrane, thereby controlling astrocyte homeostasis and CNS osmotic stability [76]. The enrichment of AQP4 on astrocytic endfeet at the blood-brain barrier is consistent with a crucial role in maintaining physiological water balance and with responding to pathological perturbations of this balance associated with ischemia or trauma [75]. Early NMO pathology is characterized by the presence of reactive astrocytes, intramyelinic edema, loss of AQP4 expression, variable perivascular deposition of $\operatorname{IgG}$ and complement components, and granulocytic leukocyte infiltration [40, 61]. Advanced lesions demonstrate more profound complement deposition, loss of myelin, and astrocyte destruction. Astrocytic responses in NMO range from sublytic gliosis to overt lysis, and these responses are frequently observed in regions without myelin loss, suggesting that NMO is a primary astrocytopathy associated with secondary demyelination [39]. Such a model for NMO pathogenesis is consistent with observations of water dyshomeostasis [62], lesion reversibility [41, 42, 80], and behavioral sequelae in NMO patients [59].

AQP4 is also expressed at the pial glia limitans, the ependyma, and the choroid plexus [53, 61]. Notably, differential cell-cell junction expression at these barrier sites [78] may provide a unique route for $\mathrm{NMO} \operatorname{IgG}$ to enter the cerebrospinal fluid (CSF) and access AQP4-expressing targets in the brain parenchyma. Recently, loss of AQP4 expression was observed in cortical layer I in NMO tissue and was associated with cognitive impairment and a corresponding loss of neurons in cortical layer II [65]. This finding suggests that subpial AQP4 was targeted by NMO IgG and indicates that astrocytopathy outside of the typical periventricular lesion may have profound pathogenic and neurologic consequences. However, at present, little is known about the pathology of CSF-brain and blood-CSF barriers in NMO patients. Therefore, in this study, we analyzed astrocyte and microglia reactivity, AQP4 expression level, and complement deposition at these interfaces.

\section{Materials and methods}

\section{Study design and series}

This study was approved by the Institutional Review Board of Mayo Clinic, Rochester, MN (IRB 2067-99). Inclusion criteria were (i) clinical and pathological diagnosis of NMO or NMOSD; (ii) sufficient archival tissue for pathological analysis; and (iii) no evidence of alternative diagnosis. Twenty-three autopsy cases met the inclusion criteria (315 total tissue blocks) (Supplemental Figure 1). Table 1 provides demographics for the patient cohort. As controls, we included five multiple sclerosis (MS) cases (79 blocks; 4 relapsing remitting MS, 1 secondary progressive MS) and five control cases without known CNS disease (45 blocks). As additional controls for choroid plexus disease, we included five hydrocephalus cases (five blocks) and five papilloma cases (five blocks). We analyzed supratentorial brain (including optic nerve), brain stem, cerebellum, and spinal cord for histopathological abnormalities in the pial surface, ependyma, and choroid plexus. To reduce anatomical variability in the choroid plexus analysis, we specifically assessed the choroid plexus in the fourth ventricle at the level of the medulla.

\section{Neuropathological evaluation}

Formalin-fixed paraffin-embedded $5 \mu \mathrm{m}$ thick sections were stained with hematoxylin and eosin (H\&E), Luxol fast blue, and periodic acid Schiff (LFB/PAS), and modified Bielschowsky silver. Immunohistochemistry was performed with the avidin-biotin-complex method as previously reported [40], using primary antibodies against glial fibrillary acidic protein (GFAP, 1:100, DAKO, Denmark), neurofilament (1:800, steam antigen retrieval with citric acid buffer pH 6.0, DAKO, Denmark), AQP1 (1:250; Santa Cruz), AQP4 (1:250, Sigma-Aldrich, USA), myelin proteolipid protein (PLP, 1:500, Serotec, Oxford, UK), KiM1P (pan-macrophage marker, 1:5000, from Dr. Wolfgang Bruck, Germany), complement C9 neo-antigen (C9neo, monoclonal B7 and polyclonal, 1:200, from Professor Paul Morgan, Cardiff, UK), and human IgG gamma chain (1:200, DAKO, Denmark).

Table 1 Demographic and clinical summaries

\begin{tabular}{ll}
\hline Characteristic & Summary \\
\hline Number of subjects & 23 \\
Sex, male:female & $2: 21$ \\
Age at symptom onset, years & $49(12-73)$ \\
Diagnosis, $n(\%)$ & \\
NMO & $18(78 \%)$ \\
NMO spectrum disorder & $5(22 \%)$ \\
AQP4-IgG serostatus, positive:negative & \\
Number of clinical attacks & $9: 0$ \\
Disease duration, months & $3(2-7)$ \\
Age at death, years & $36(8-240)$ \\
\hline
\end{tabular}

Unless otherwise indicated values shown are median (range). Note: age of symptom onset and disease duration missing for one patient; number of clinical attacks missing for two patients; AQP4-IgG serology missing for 14 patients

${ }^{\text {a }}$ Sera available for testing in nine patients. Other subjects either lacked sera or preceded the availability of serological testing 
We systematically analyzed the pial surface, ependyma, and choroid plexus for histopathological alterations, and assessed AQP4 immunoreactivity, the pattern of macrophage/microglial reaction, and the presence of C9neo deposition. The patterns observed in NMO tissue were compared to the corresponding anatomical areas in MS and controls. For quantitation of AQP4 loss, the entire pia available on the tissue block was assessed for AQP4 immunoreactivity. The pattern of AQP4 reactivity was defined as focal when loss was restricted to a single high-power field at 40X, or diffuse when extending beyond one such field. Because of variation in the extent of the diffuse involvement and to help differentiate between the situation, where diffuse loss encompassed the bulk of the pial surface versus when the diffuse loss was relatively isolated, we categorized the diffuse loss as occupying $<25,25-50,50-75$, or $>75 \%$ of the total length of pia available for analysis.

\section{Results}

\section{Pial glia limitans}

At the pial surface of the cerebral cortex, normal control tissue showed minimal microglial reactivity (KiM1P expression) (Fig. 1a), abundant AQP4 immunoreactivity (Fig. 1d), and no evidence of complement C9neo deposition (Fig. 1g). Widespread microglial
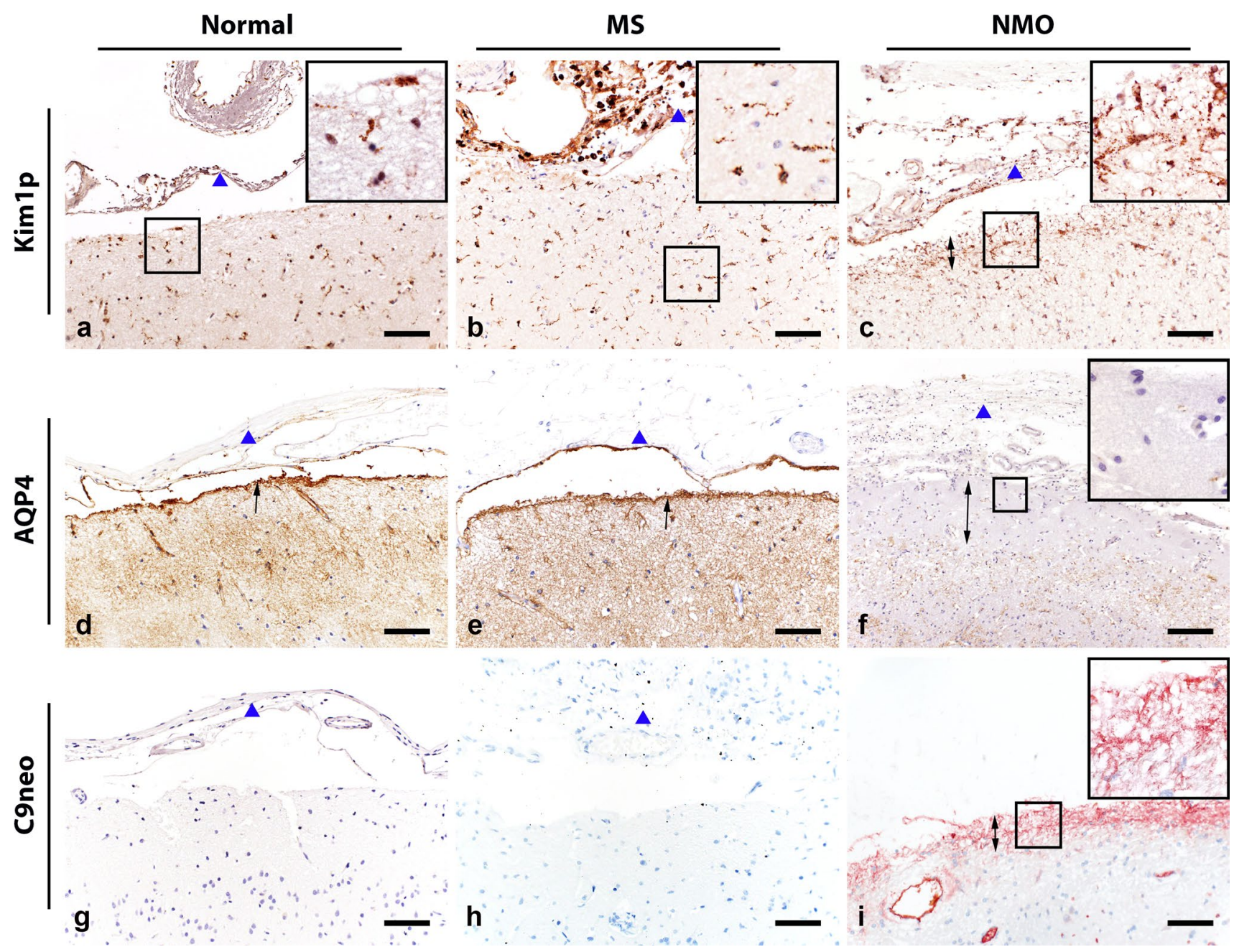

Fig. 1 Pial pathology in normal, MS, and NMO tissues. Supratentorial brain tissue from neurologically normal controls (a, d, g), MS (b, $\mathbf{e}, \mathbf{h})$, and $\operatorname{NMO}(\mathbf{c}, \mathbf{f}, \mathbf{i})$. Microglial reactivity is minimal at the pial interface in normal control tissue (a), prominent in MS meninges, with diffuse extension into the cortical parenchyma (b), and concentrated in the glial limitans and in the upper molecular layer (between arrowheads) in NMO (c). AQP4 immunoreactivity is abundant at the glia limitans in normal control (d) and MS (e) (arrows), but lost or markedly reduced along the cortical surface in NMO (f; between arrowheads). Complement C9neo immunoreactivity is not detected at the pia in normal control $(\mathbf{g})$ or MS $(\mathbf{h})$, but concentrated at the pia in NMO (i; between arrowheads). Immunohistochemistry for KiM1P (a-c), AQP4 (d-f), and C9neo (g-i). Meninges marked by block up pointing triangle. Scale bars $100 \mu \mathrm{m}$ 


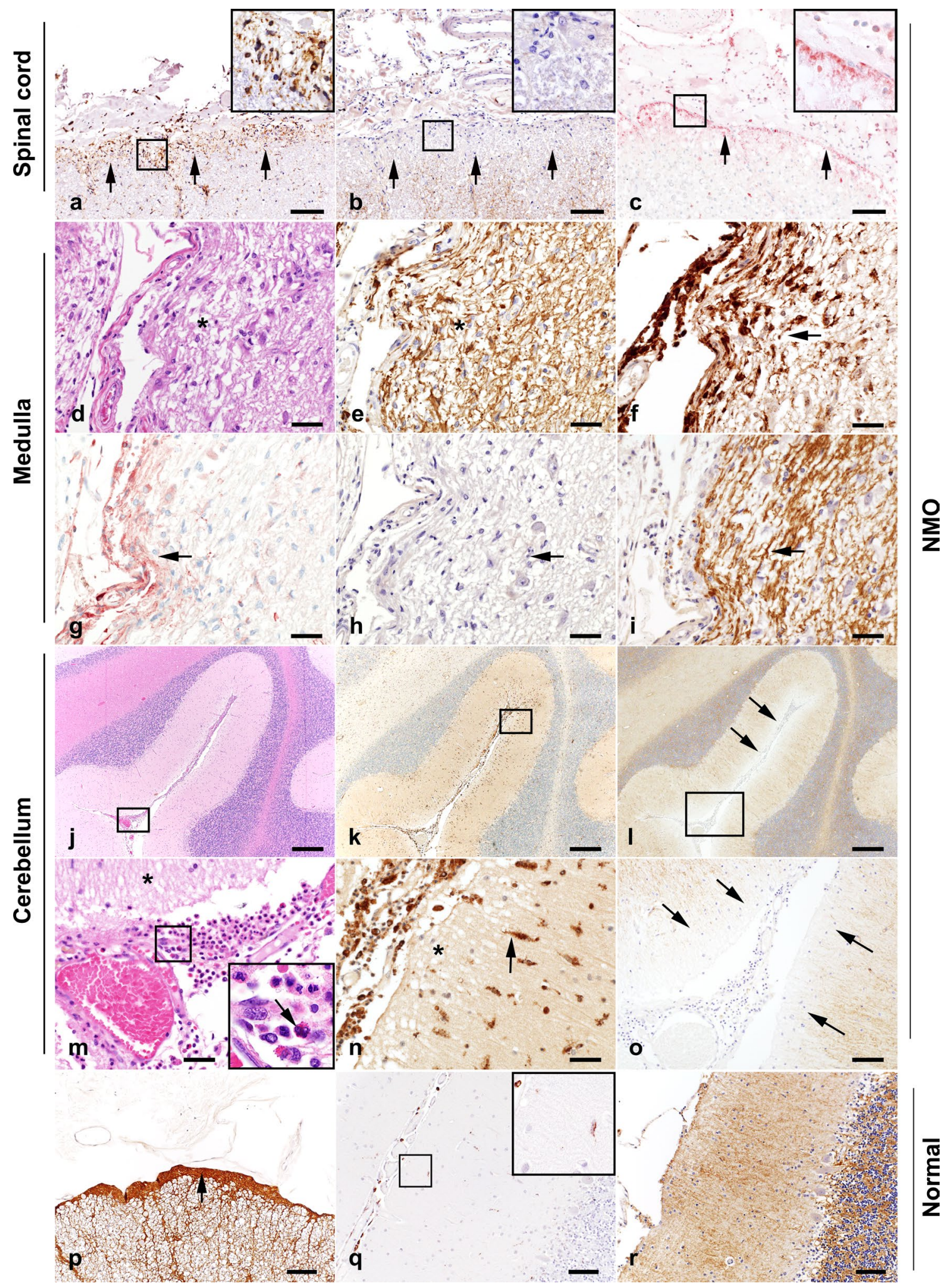

reactivity, in both the meninges and subpial cortex, was observed in MS tissue (Fig. 1b), but AQP4 immunoreactivity was normal (Fig. 1e) and C9neo deposition was not detected (Fig. 1h). In contrast, in NMO tissue, there was accumulation of reactive microglia (Fig. 1c), near complete loss of AQP4 immunoreactivity at the 
\Fig. 2 Pial pathology in NMO. Spinal cord (a-c): Microglial reactivity (arrows) is concentrated at the pial glia limitans (a), colocalizing to a region of AQP4 loss (b), and C9neo deposition (c), on consecutive sections. Medulla oblongata: (d-i; consecutive sections). The subpial parenchyma exhibits mild vacuolation consistent with edema (d) H\&E), dystrophic astrocytes (e), microglial reactivity (f), C9neo deposition (g), loss of AQP4 immunoreactivity (h), and preserved myelin (i). Cerebellum (j-o): $\mathbf{j}$ Cerebellar meninges contain infiltrating eosinophils and neutrophils (H\&E; enlarged in $\mathbf{m}$ ) and subpial vacuolation (* in $\mathbf{m})$. Reactive microglia are distributed in the subpial molecular layer (k; enlarged in $\mathbf{n})$. Subpial AQP4 immunoreactivity is lost (l; enlarged in o). Normal control: AQP4 immunoreactivity is abundant at the surface of the spinal cord (p) and cerebellum $(\mathbf{r})$. Microglial reactivity is negligible in the normal cerebellum (q). Immunohistochemistry for KiM1P (a-c, f; k, n, q); AQP4 (b, h, l, $\mathbf{o}, \mathbf{p}, \mathbf{r})$; C9neo (c, g); GFAP (e); PLP (i). Scale bars in $\mathbf{a}, \mathbf{b}, \mathbf{c}, \mathbf{p}, \mathbf{q}$, and $\mathbf{r}=100 \mu \mathrm{m}$. Scale bars in $\mathbf{d}-\mathbf{i}, \mathbf{m}-\mathbf{o}=50 \mu \mathrm{m}$. Scale bars in $\mathbf{j}, \mathbf{k}$, $\mathbf{l}=200 \mu \mathrm{m}$

CSF-brain interface (Fig. 1f) and deposition of C9neo in focal regions of the pial glia limitans (Fig. 1i).

In NMO spinal cord, foci of reactive microglia (Fig. 2a), AQP4 loss (Fig. 2b; compare to normal spinal cord in Fig. 2p), and C9neo deposition (Fig. 2c) were observed at the pial glia limitans. At the pial surface of the medulla oblongata, dystrophic astrocytes (Fig. 2d, e), reactive microglia (Fig. 2f), C9neo deposition (Fig. 2g), and AQP4 loss (Fig. 2h) were observed within the context of preserved myelin (Fig. 2i). At the pial surface of the cerebellum, meningeal eosinophils and neutrophils (Fig. 2j, m) were found in proximity to regions containing reactive microglia (Fig. 2k, n; compare to normal cerebellum in Fig. 2q) and decreased or absent AQP4 immunoreactivity (Fig. 2l, o; compare to normal cerebellum in Fig. 2r). At the cerebellar pia, there was a mild loss of astrocytic processes (Supplementary Figure 2a, 2b), compared to normal cerebellum (Supplementary Figure 2c, 2d).

In 21 of 23 NMO cases (91\%), AQP4 immunoreactivity was lost and/or decreased at the pia across multiple blocks examined from a given patient (Fig. 3a). All CNS regions exhibited AQP4 loss at the pia, most frequently in spinal cord (Fig. 3b, Supplementary Figure 3). Reduced AQP4 immunoreactivity occurred in both a diffuse and focal pattern (Fig. 4), with diffuse loss ranging from less than $25 \%$ of the sampled pia, to more than $75 \%$ of the region characterized by AQP4 loss.

The majority (82\%) of NMO cases exhibited reactive microglia that were increased in both size and number (Supplementary Figure 4a, 4b). In cerebral cortex and spinal cord, the microglial reaction was preferentially distributed along the pial glia limitans, but in cerebellum, reactive cells were distributed at both the pial surface and in the subpial parenchyma. With regard to complement C9neo staining, $81 \%$ of NMO cases exhibited complement deposits at the pial surface (Supplementary Figure 5a, 5b; Table 2).
Colocalization of microglial activation, AQP4 loss, and C9neo deposition at the pia was only observed in NMO tissue and never in controls or MS samples. Furthermore, all 23 NMO cases exhibited pial and subpial tissue vacuolation characterized by enlarged spaces between astrocytic processes (Fig. 2d, n). In some regions, this was coincident with dystrophic or hypertrophic astrocytes (Fig. 2e). Subpial calcifications (Fig. 5a, b) and infiltrating inflammatory cells (Fig. 5c) were also observed at the pial glia limitans in both NMO brain and spinal cord. Focal subpial myelin loss (Fig. 5f) was evident in the brain stem and spinal cord white matter, but not in the cortex. In some regions of myelin loss, axons were remyelinated by CNS-infiltrating Schwann cells (Fig. 5d, e).

\section{Ependyma}

The ependyma is formed by a continuous layer of ciliated ependymocytes arranged in a simple columnar organization that separates the ventricle from the parenchyma (Fig. 6a). In normal control tissue ependymal cells expressed abundant AQP4 enriched on the basolateral membrane (Fig. 6c) in the absence of reactive microglia (Fig. 6b) or C9neo deposition (Fig. 6d). In MS tissue, focal discontinuities in the ependymal layer were occasionally observed (Fig. 6e) and the ependymocytes present exhibited increased AQP4 immunoreactivity (Fig. 6g). While subependymal reactive microglia (Fig. 6f) were variably found in MS tissues, there was no evidence of $\mathrm{C} 9$ neo deposition in or near the ependyma (Fig. 6h). In contrast, all 16 NMO cases with ependymal tissue available for analysis exhibited loss of ependymocytes and these discontinuities were typically associated with subependymal gliosis and glial nodules extending into the ventricle (Fig. 6i). Where the ependymal layer remained intact, the cells were frequently characterized by an atrophic, flattened morphology, and irregular organization (Fig. 6j), including the presence of periventricular ependymal rosettes. This disorganized ependyma was also associated with variable eosinophilic infiltration (Fig. 6k) and the presence of granulocytes along the CSF face of the layer and in the subependymal parenchyma (Fig. 61).

AQP4 immunoreactivity was lost from preserved ependymocytes across multiple blocks among 56\% of $16 \mathrm{NMO}$ cases with available tissue (Fig. 7a, b), often extending into the subependymal parenchyma (Fig. 6o). A combination of subependymal astrocyte reactivity with variable astrocyte loss was evident in these regions (Supplementary Figure 6). In some cases, AQP4 was lost from intact ependymocytes but preserved in the parenchyma, suggesting early involvement at the CSF interface (Fig. 6p). All but one of the 16 NMO cases $(94 \%)$ also exhibited reactive microglia in the ependymal layer (Fig. 6n and Supplementary Figure 7) 
Fig. 3 Quantification of pial AQP4 immunoreactivity. AQP4 immunoreactivity in the pia was assessed in multiple blocks from individual patients (a). A range of AQP4 expression was observed. Dark blue circles enumerate blocks with AQP4 loss; light blue circles represent blocks that showed reduced AQP4 but not complete loss, and gray circles are blocks with normal or increased AQP4. The number of NMO cases exhibiting AQP4 loss versus AQP4 preservation in the pia in at least one block was determined across anatomical regions and expressed as percentages (b) a AQP4 immunoreactivity in pia by individual

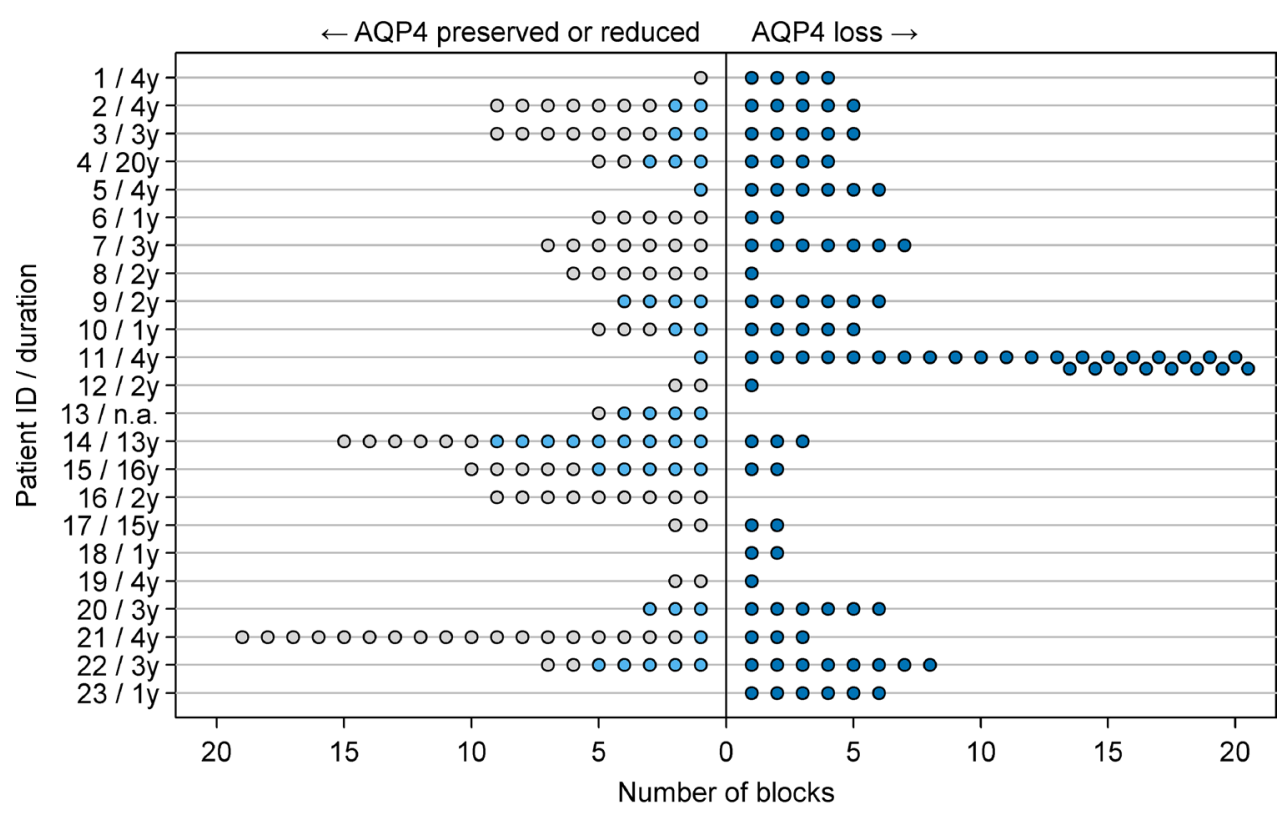

b Number and percent of individuals with APQ4 loss in pia

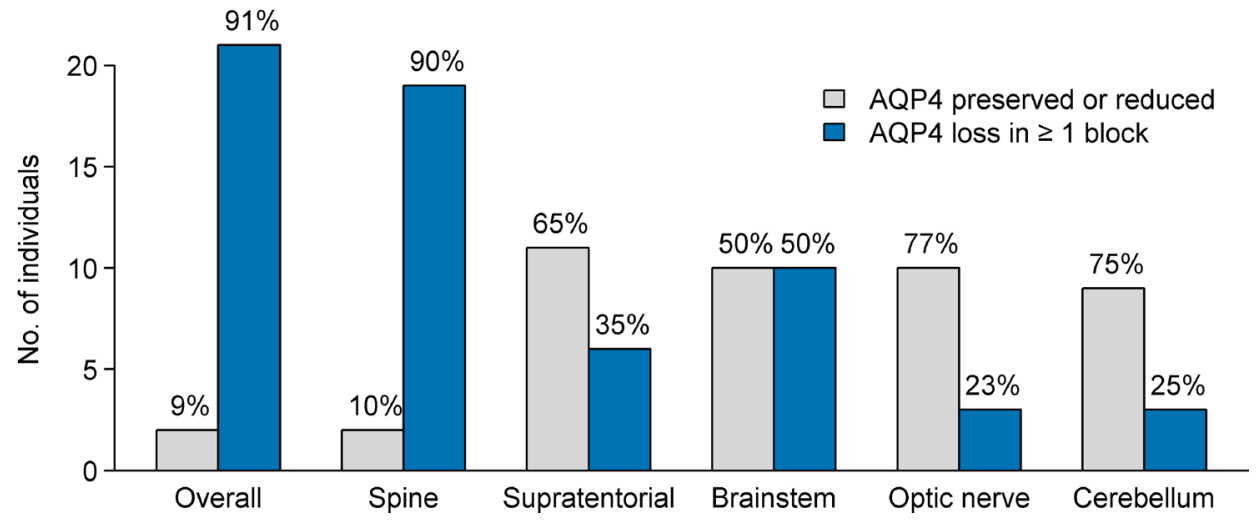

and about a third (38\%) of cases showed C9neo deposition preferentially localized to the ependymocytes (Fig. $6 \mathrm{~m}$ and Supplementary Figure 8).

\section{Choroid plexus}

In normal controls, approximately $40 \%$ of choroid plexus epithelial cells demonstrate AQP4 immunoreactivity in the cytoplasm and at the basolateral membrane (Fig. 8a, arrows). In general, AQP4 expression was more abundant in choroid plexus adjacent to the wall of the fourth ventricle. AQP1 immunoreactivity was more uniform in normal choroid plexus and predominantly localized to the epithelial cell apical membrane (Fig. 8b). Compared to normal control tissue, the choroid plexus in hydrocephalus cases exhibited more pronounced basolateral AQP4 immunoreactivity (Fig. 8c) and increased AQP1 immunoreactivity in the cytoplasm and at the apical plasma membrane (Fig. 8d).
All five papilloma cases showed focal clusters of tumor cells with increased AQP4 immunoreactivity in both the membrane and cytoplasm, without apparent polarization (Fig. 8e). AQP1 immunoreactivity remained polarized to the apical membrane in papilloma tissue, but the staining pattern was heterogeneous (Fig. 8f). AQP4 immunoreactivity was normal or increased in MS choroid plexus (Fig. 8g), and apical AQP1 immunoreactivity was increased in some cases (Fig. 8h). In contrast, in all 12 NMO cases with choroid tissue available, choroid plexus epithelial cells demonstrated a near complete loss of AQP4 immunoreactivity (Fig. 8i), whereas AQP1 immunoreactivity was preserved (Fig. 8j).

Further analysis of NMO cases confirmed that while the gross structure of choroid plexus did not appear disrupted (Fig. 9a), AQP4 immunoreactivity in the choroid epithelial cells was reduced or lost from the basolateral membrane (Fig. 9b). In contrast, the intact choroid plexus 


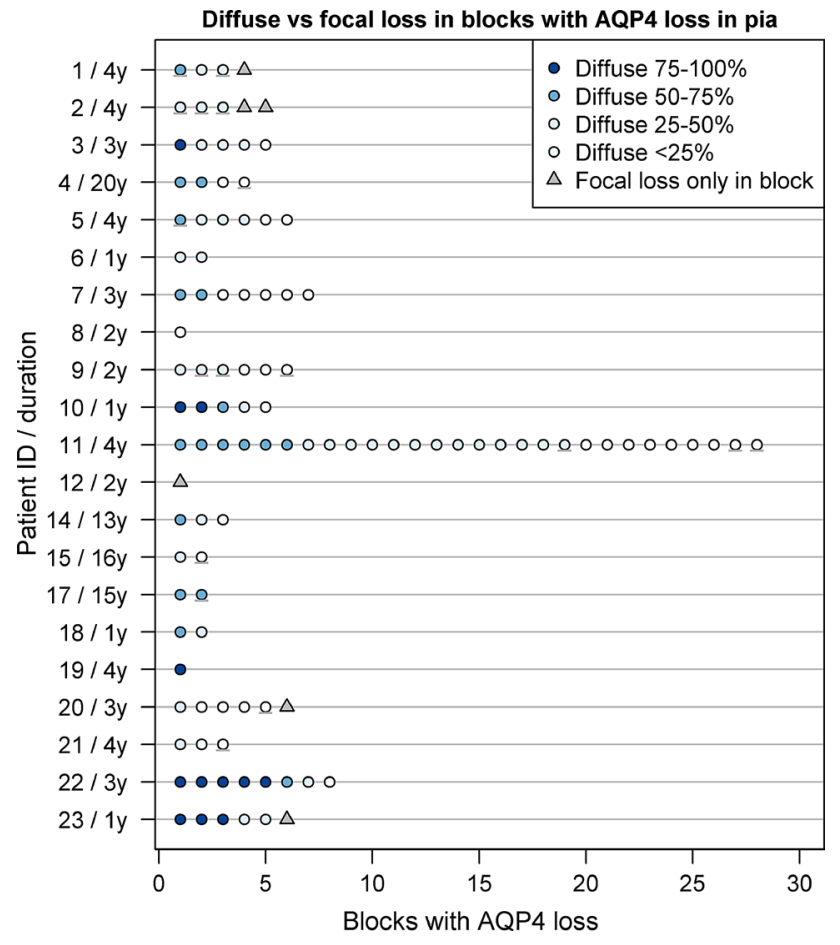

Fig. 4 Pattern of pial AQP4 immunoreactivity loss in individual NMO patients. Among 21 NMO cases (107 blocks), the pattern of pial AQP4 loss was characterized as focal or diffuse. Subjects exhibiting diffuse AQP4 loss were further graded based on the percentage of pial involvement ranging from $<25 \% ; 25-50 \% ; 50-75 \%$, and $>75 \%$ loss. Each symbol represents one block; symbol shape represents pattern of loss; and color indicates percentage of pia demonstrating diffuse AQP4 loss. Blocks exhibiting both diffuse and focal patterns are indicated with a gray line under the color-coded diffuse pattern symbol. Patient identifiers and disease duration are shown on the $y$-axis

in MS cases (Fig. 9g) exhibited normal or increased AQP4 immunoreactivity (Fig. 9h). The number and size of stromal KiM1P-positive cells were increased in $86 \%$ of NMO cases (Fig. 9c), while only scattered KiM1P-positive macrophages/microglia were observed in the MS cases (Fig. 9i). C9neo deposition was observed in perivascular regions of the plexus stroma and in stromal concretions in both NMO (arrowhead in Fig. 9d) and MS cases (arrowhead in Fig. 9j). However, extensive C9neo immunoreactivity was exclusively found on the membrane of choroid plexus epithelial cells in $40 \%$ of NMO cases (Fig. 9d), a pattern that was not observed in any of the MS cases. Membrane Ig deposition was present on choroid epithelial cells in NMO (Fig. 9e, f), but restricted to the choroid stroma in MS (Fig. 9k, 1).

\section{Discussion}

This study provides the first evidence for involvement of CSF-brain and blood-CSF interfaces at the pial glia
Table 2 Comparison of pathology at CSF-brain and blood-CSF interfaces

\begin{tabular}{llll}
\hline & NMO & MS & Normal \\
\hline $\begin{array}{llll}\text { Pial surface } \\
\text { C9neo deposition }\end{array}$ & Yes (17/21) & Yes (2/5) & No \\
Microglial reaction & & & \\
Localized to pia & Yes (18/22) & Yes & No \\
Extended into cortex & Rare & Yes & No \\
Associated with CDM & No & No & No \\
AQP4 loss & Yes (21/23) & No (increased) & No \\
Ependyma & & & \\
C9neo deposition & Yes (6/16) & Yes (1/5) & No \\
Microglial reaction & Yes (16/16) & Scattered (2/5) & No \\
AQP4 loss & Yes (9/16) & No (increased) & No \\
Ependymal discontinuity & Yes (16/16) & Yes (5/5) & Rare \\
Choroid plexus & & & \\
C9neo deposition & & & No \\
On epithelial mem- & Yes (4/10) & No & Yes (rare) \\
brane & & & Minimal \\
In stroma & Yes & Yes & No \\
Microglial reaction & Moderate & Mild & No (increased) \\
AQP4 loss & Yes (12/12) & & \\
\hline
\end{tabular}

$C D M$ cortical demyelination

a Epithelial cells in the normal choroid plexus of the fourth ventricle express AQP4. In NMO, AQP4 loss was reflected by a decrease in the number of positive cells and by reduced AQP4 staining intensity on positive cells

limitans, the ependymal surface, and the choroid plexus in the histopathology of NMO (Table 2). At the pial glia limitans, AQP4 loss was colocalized with dystrophic astrocytes, microglial reactivity, and $\mathrm{C} 9$ neo deposition. AQP4 loss at the pial surface also colocalized with meningeal infiltration of eosinophils and neutrophils. Likewise, the ependymal lining of ventricles in NMO tissue exhibited loss of ependymocytes and structural disorganization associated with the presence of subependymal reactive astrocytes, loss of AQP4 expression at both the ependymal surface and in the parenchyma, microglial reactivity, C9neo deposition, and granulocytic infiltrates at the CSF face of the ependymal layer. Finally, the choroid plexus in NMO tissues exhibited profound loss of AQP4 expression, an increase in number of stromal macrophages, and deposition of immunoglobulins and complement activation factors on choroid epithelial cell membranes. These changes were never observed in control tissues. The specificity of AQP4 loss in the choroid plexus in NMO cases was confirmed by the coincident retention of normal levels of AQP1 immunoreactivity. While MS cases did exhibit microglial reactivity and some evidence of stromal complement deposition, the pattern and extent of pathology were markedly different from NMO, indicating a unique pathology involving CSF interfaces 


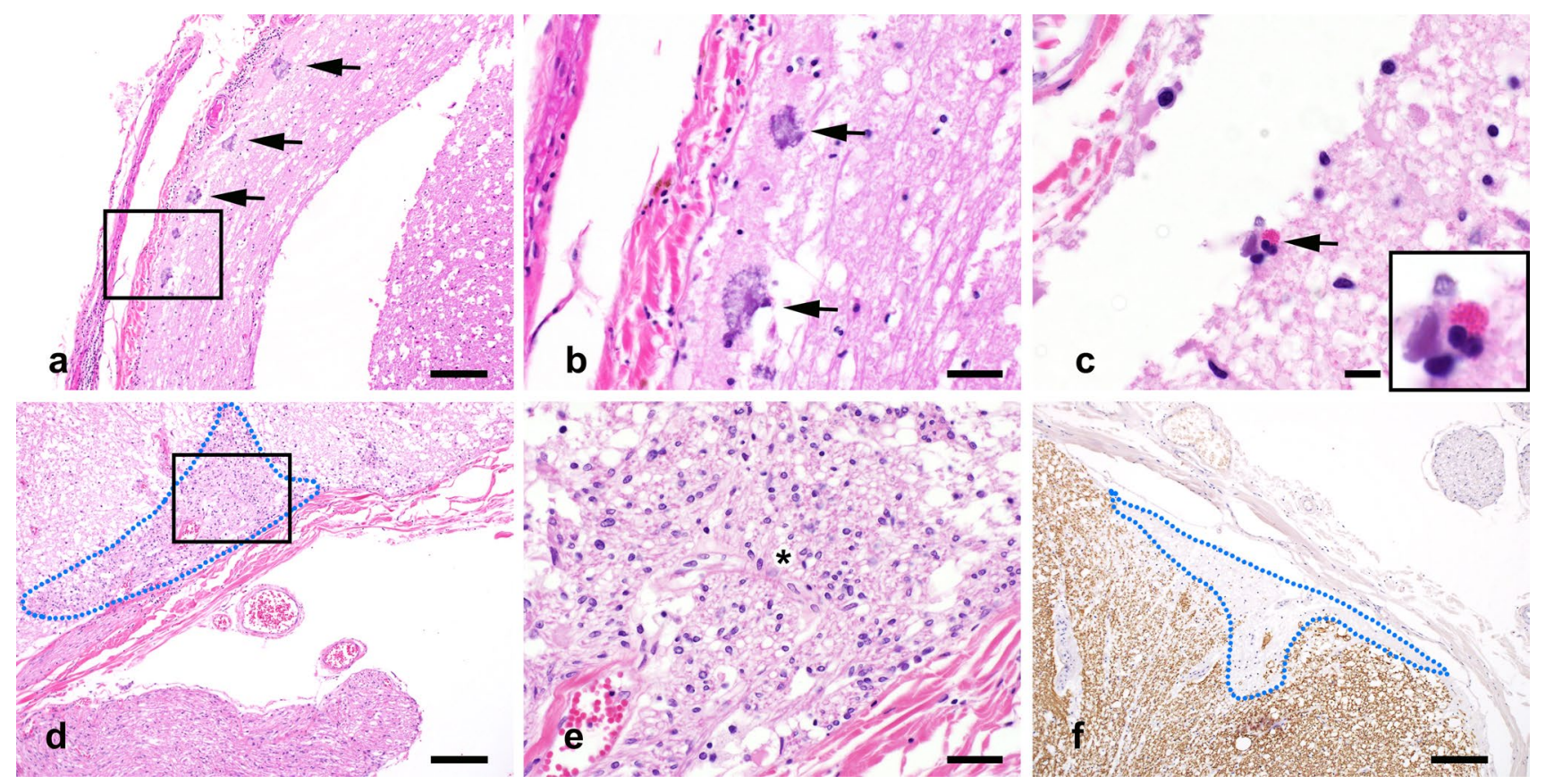

Fig. 5 Spectrum of subpial histopathological alterations in NMO. Calcifications are observed in the spinal pial glia limitans (a; arrows; enlarged in $\mathbf{b} ; \mathrm{H} \& \mathrm{E})$. An eosinophil is present in the pial glia limitans immediately below the spinal leptomeninges (c; arrow; H\&E). Invading Schwann cells (circled with blue dotted line) are found in the spi- nal cord at the dorsal root entry zone (d; enlarged in $\mathbf{e}$; H\&E). Focal subpial myelin loss (circled with blue dotted line) is observed in the spinal cord (f; PLP). Scale bars in a, $\mathbf{d}$, and $\mathbf{f}=200 \mu \mathrm{m}$. Scale bars in $\mathbf{b}$ and $\mathbf{e}=50 \mu \mathrm{m}$. Scale bars in $\mathbf{c}=10 \mu \mathrm{m}$ in NMO that mirrors the pathology at blood-brain interfaces. Notably, while the glia limitans superficialis and the glia limitans perivascularis share a primary involvement of AQP4-expressing astrocytic foot processes, the ependymal and choroid plexus barriers are comprised of non-astrocytic cells expressing AQP4. Thus, while NMO is certainly a primary astrocytopathy, the disease also has an important component of an "AQP4-opathy" that involves antibodymediated injury to other CNS cell types that express the water channel. As with our previous report demonstrating that sarcolemmal AQP4 is a target of IgG in patients with NMO [19], these observations further expand the cellular repertoire of NMO IgG targets beyond the archetypal astrocyte.

Ependymoglial lineage cells exhibit apical-basal polarization and the expression of basolateral membrane specializations that facilitate contact with mesenchymal borders [10]. These specializations anchor the basolateral membrane of ependymoglial cells to the basal lamina of mesenchymal cells via interactions between laminin, $\alpha$-dystroglycan, and $\beta$-dystroglycan [73]. Thus, astrocytic endfeet interact with capillary endothelial cell and meningeal fibroblast basement membranes to form the blood-brain barrier and the CSF-brain barrier, respectively [69], and choroid plexus epithelial cells interact with capillary endothelial cell basement membranes to form the
blood-CSF barrier [28, 37]. These physical mesenchymal-ependymoglial barriers are vital to the maintenance of the unique CNS interstitial fluid composition required for normal neuronal function. Of note, AQP4 is a component of the dystrophin-associated protein complex and is, therefore, polarized to the basolateral membrane of ependymoglial cells, bringing the water channel into proximity with the mesenchymal borders [50]. Indeed, this localization is fundamental to water, ion, and protein exchange between the blood, the brain parenchyma, and the CSF [1].

The blood-brain barrier is formed at tight junctions between capillary endothelial cells within the brain parenchyma, preventing diffusion of blood-borne ions and proteins into the perivascular stroma. The endfeet of perivascular astrocytes, along with accessory cells, such as pericytes, provides a second layer of control over solute flow from blood to parenchyma, resulting in a two-step process of facilitated movement across the endothelial cell barrier and then across the astrocyte barrier [69]. In contrast, the blood-CSF barrier at the choroid plexus is physically manifested by the apical tight junctions found between choroid plexus epithelial cells. The endothelial cells at this interface are fenestrated and lack tight junctions, permitting diffusion of ions and proteins into the choroid stroma [74]. Pathogenically, this difference has a profound consequence for accessibility of NMO IgG to AQP4. At the blood-brain 


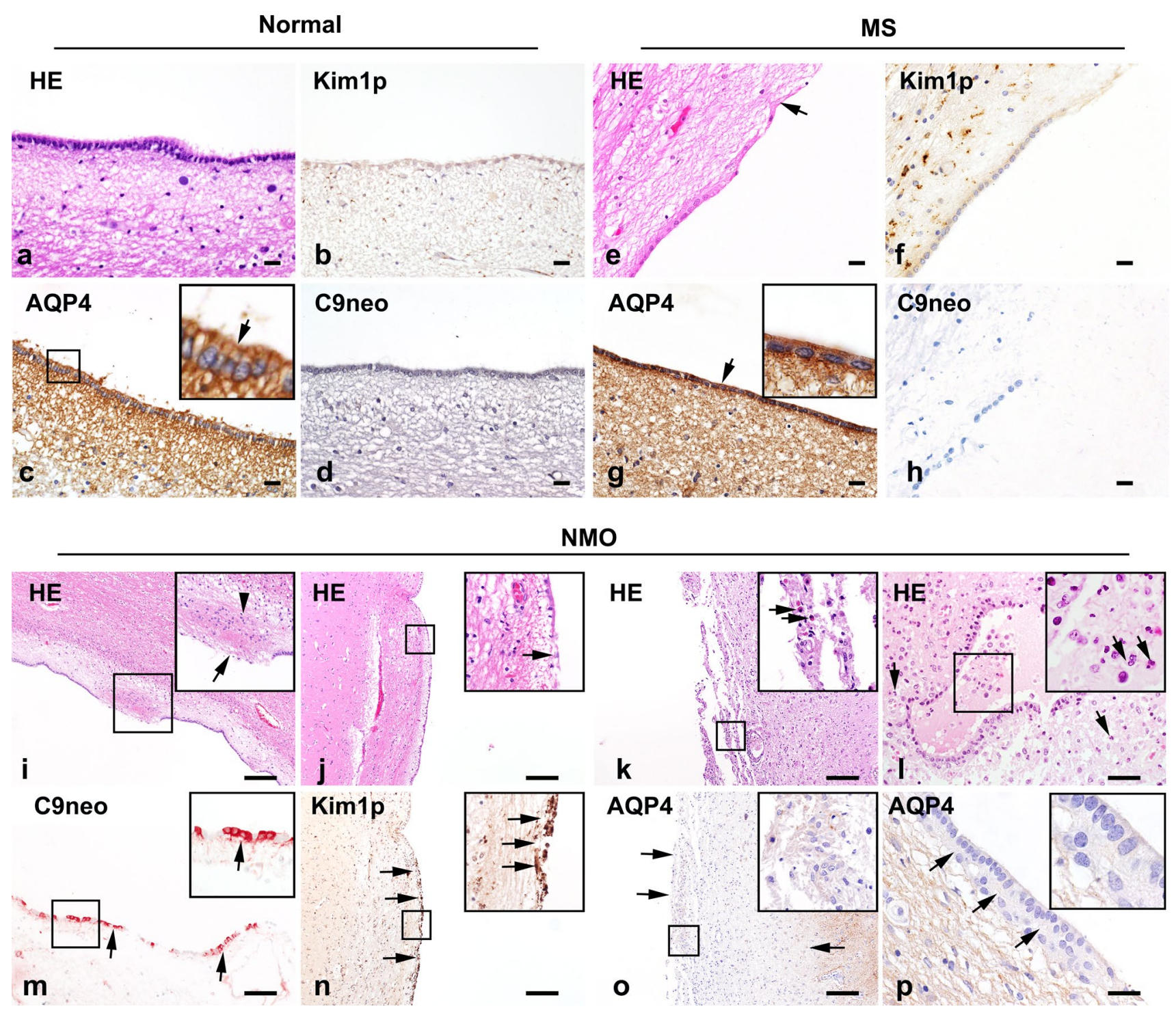

Fig. 6 Ependymal pathology in normal, MS, and NMO tissues. Normal control: Ependymocytes show ciliated simple columnar morphology lining the ventricle (a). Minimal microglial reactivity is present (b), AQP4 immunoreactivity is abundant on ependymocytes and in the subependymal parenchyma (c), and C9neo is not detected (d). MS: Focal ependymal loss is present in MS (e; arrow). Reactive microglia are found in the subependymal parenchyma but not in the ependymal layer (f); AQP4 immunoreactivity is increased at the ependyma (g; arrow), but C9neo is not present (h). NMO: Ependymocytes are lost (arrow) and a subependymal glial nodule (arrowhead) bulges into the ventricle (i). Discontinuous atrophic ependymal cells (arrow) are flattened along the ventricle wall (j). Infiltrating

barrier, circulating NMO IgG has limited access to AQP4 on perivascular astrocytic endfeet. However, at the bloodCSF barrier, NMO IgG could readily enter the perivascular space and encounter AQP4 on the basolateral surface of the choroid epithelial cells.

Robust AQP4 expression on the basolateral surface of choroid plexus epithelial cells in normal tissue coupled to

eosinophils (arrows) are present beneath a disorganized ependymal layer (k). Abundant granulocytes are found on the CSF face of preserved ependyma and in subependymal parenchyma (l). C9neo immunoreactivity is observed on ependymocytes (m). A consecutive section to (j) demonstrates microglial reactivity (arrows) at the ependymal layer (n). AQP4 loss (o) is extensive in both the ependyma and subependymal regions of a section consecutive to (k). Focal loss of ependymal AQP4 immunoreactivity is observed with preservation of subependymal AQP4 (p). Scale bars in $\mathbf{a}-\mathbf{h}=20 \mu \mathrm{m}$. Scale bars in $\mathbf{i}-\mathbf{k}$, $\mathbf{n}$, and $\mathbf{o}=200 \mu \mathrm{m}$. Scale bars in $\mathbf{l}, \mathbf{m}$, and $\mathbf{p}=100 \mu \mathrm{m}$. Immunohistochemistry for KiM1P (b, f, n); AQP4 (c, g, o, p); C9neo (d, h, m); and $\mathrm{H} \& \mathrm{E}(\mathbf{a}, \mathbf{e}, \mathbf{i}-\mathbf{l})$

the presence of immunoglobulin immunoreactivity and the nearly complete loss of AQP4 expression in these cells in NMO tissue indicates that the blood-CSF barrier may be a primary site for entry of NMO IgG into the CNS. In fact, immunoglobulins have been detected within the choroid plexus stroma in healthy normal controls [52], as well as in both neurological and non-neurological disease conditions, 
a AQP4 immunoreactivity in ependyma by individual

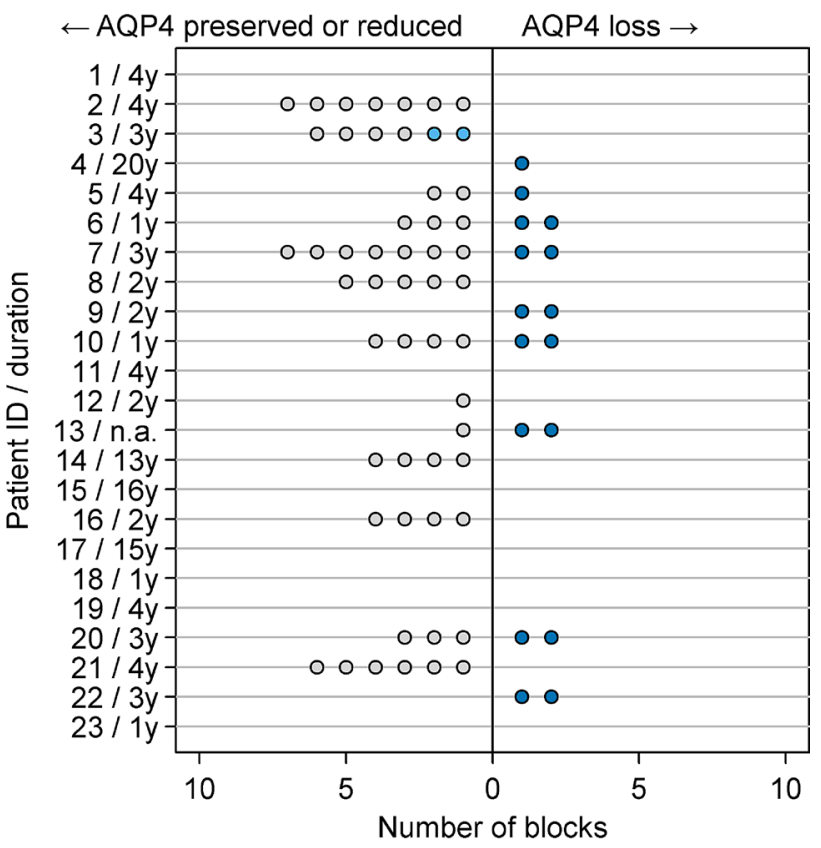

\section{b Number and percent of individuals with APQ4 loss in ependyma}

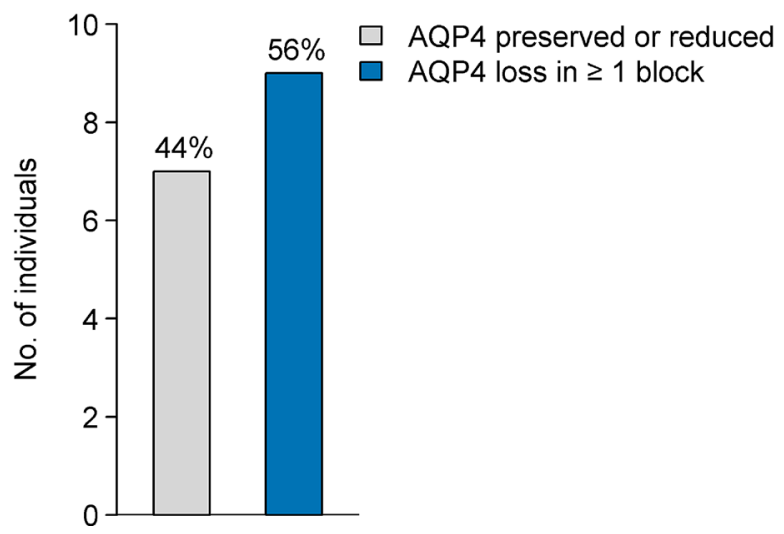

Fig. 7 Quantification of ependymal AQP4 immunoreactivity in NMO. AQP4 immunoreactivity in the ependyma was assessed in multiple blocks from individual patients (a). A range of AQP4 expression was observed. Dark blue circles enumerate blocks with AQP4 loss; light blue circles represent blocks that showed reduced AQP4 but not complete loss; and gray circles are blocks with normal or increased AQP4. Patient identifiers and disease duration are shown on the $y$-axis. The number of NMO cases exhibiting AQP4 loss versus preservation in the ependyma in at least one block was determined and expressed as a percentage (b)

such as Alzheimer disease, systemic lupus erythematosus, and others $[3,4,9,13,17,46,55,56,66,67,81]$. Of note, we also detected robust immunoreactivity for $\mathrm{C} 9$ neo at the

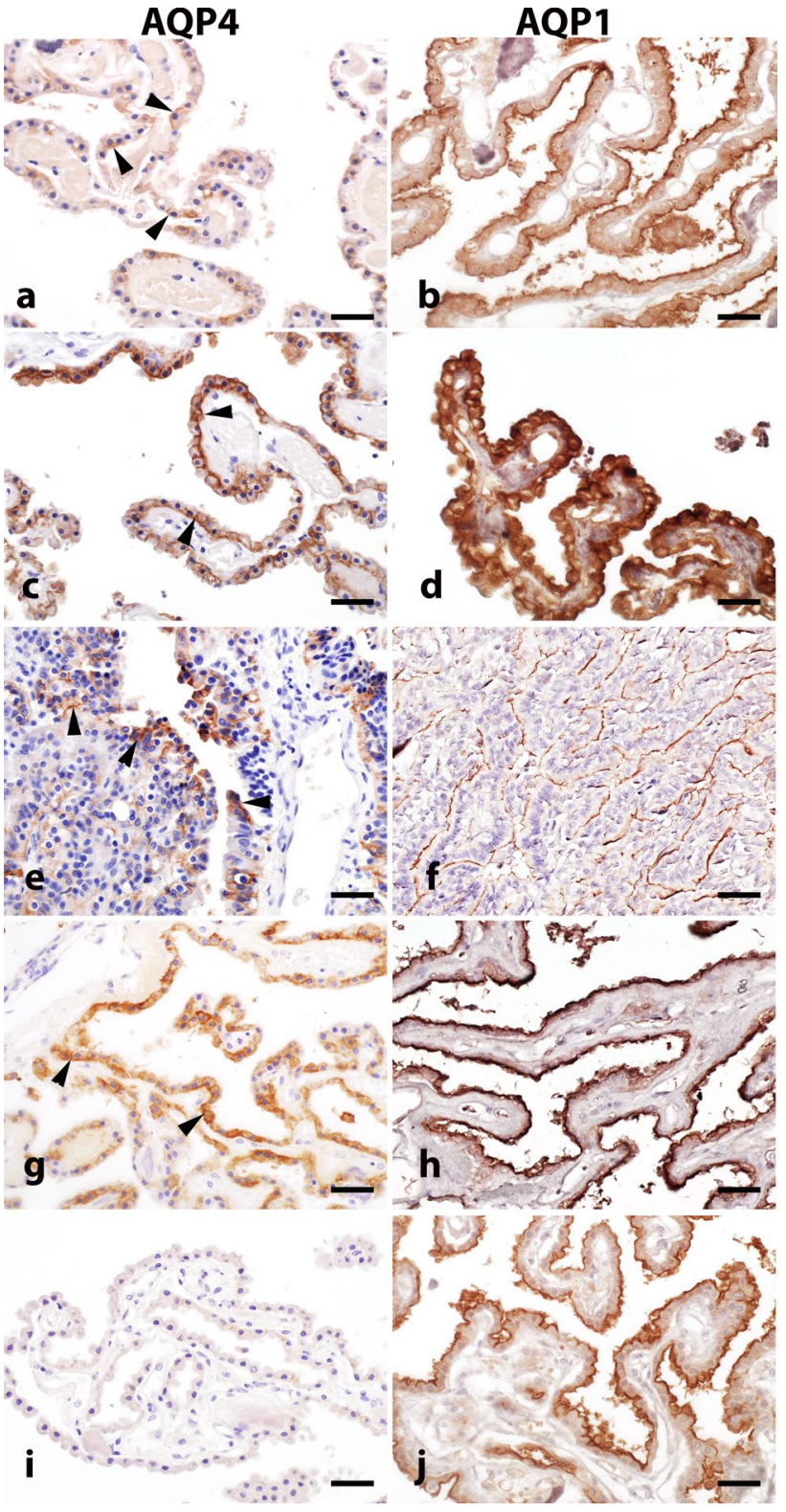

Fig. 8 Patterns of AQP4 and AQP1 expression in the choroid plexus. Normal choroid plexus epithelial cells exhibit variable AQP4 immunoreactivity in the basolateral membrane and cytoplasm (a; arrowheads highlight positive cells), whereas AQP1 is distributed uniformly at the apical membrane in normal choroid plexus epithelial cells (b). In hydrocephalus, both AQP4 (c) and AQP1 (d) immunoreactivity are increased throughout the choroid epithelium. AQP4 immunoreactivity is focally increased in papilloma (e; arrowheads), while AQP1 expression (f) is more variable and abnormal. In multiple sclerosis, AQP4 immunoreactivity in the choroid plexus is either normal or increased (g; arrowheads) with more pronounced AQP1 immunoreactivity (h). In NMO, AQP4 immunoreactivity is greatly reduced or entirely absent in the choroid plexus (i); however, AQP1 immunoreactivity is normal (j). Scale bars $20 \mu \mathrm{m}$. Immunohistochemistry for AQP4 (a, c, e, g, i) and AQP1 $(\mathbf{b}, \mathbf{d}, \mathbf{f}, \mathbf{h}, \mathbf{j})$ 


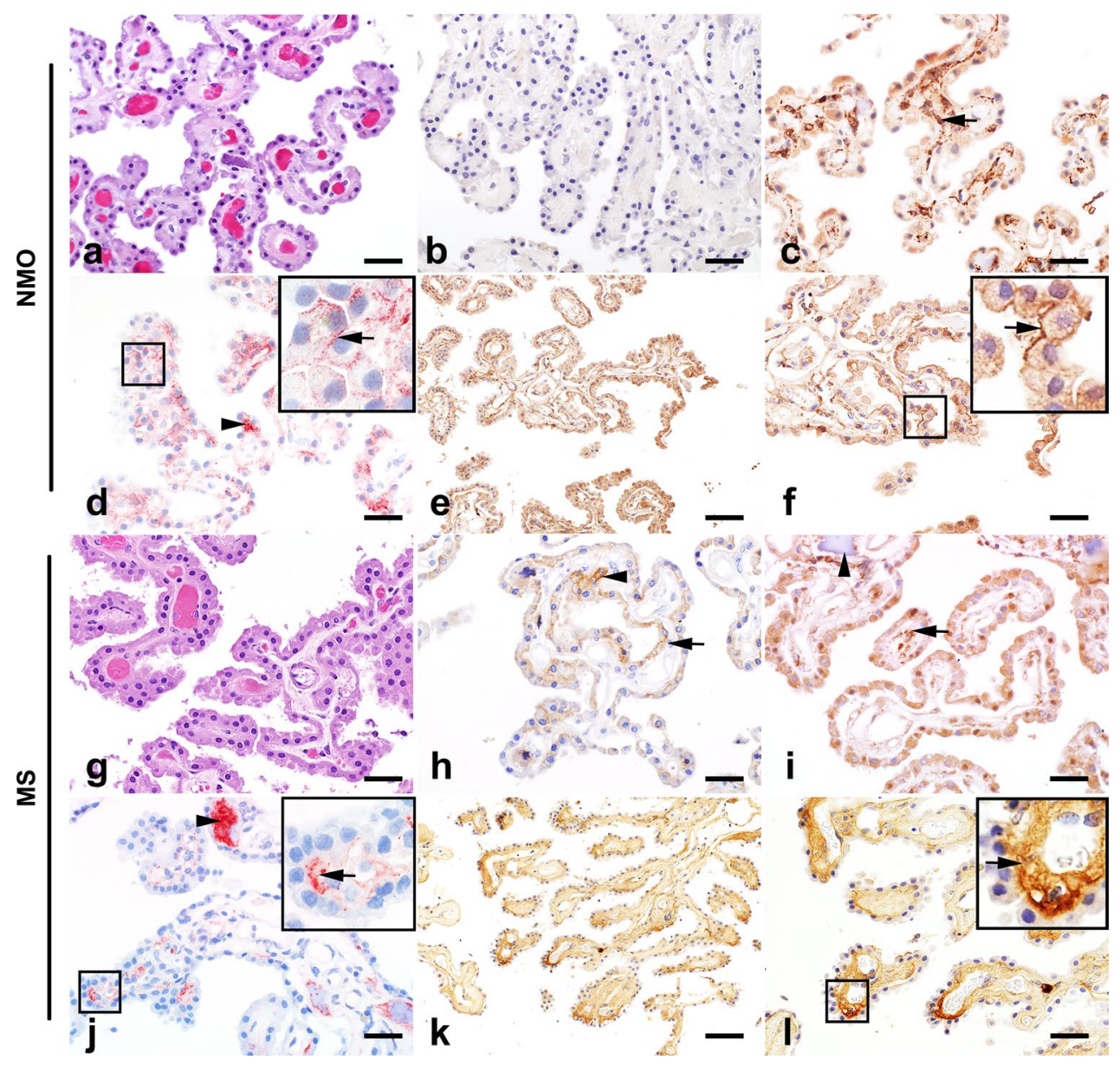

Fig. 9 Choroid plexus pathology in NMO and MS. NMO: Intact choroid plexus (a; H\&E) exhibits extensive AQP4 loss (b) and increased macrophage density (c). C9neo deposition is observed in stromal concretions ( $\mathbf{d}$; arrowhead) but also on choroid epithelial cell membranes (d inset; arrow). IgG immunoreactivity is also observed in the choroid plexus (e) with intense IgG immunoreactivity on the membrane of choroid plexus epithelial cells (f; inset). MS: Choroid plexus (g; H\&E) shows preserved AQP4 (h). Scattered macrophages are found in the stroma (i; arrows), as well as calcifications (i; arrow-

blood-CSF barrier in NMO tissues, with a pattern that suggested deposition along the choroid plexus epithelial cell membrane. Complement factors, ranging from $\mathrm{C} 1 \mathrm{q}$ through to $\mathrm{C} 9$ neo, are also observed in the choroid plexus in multiple conditions, including MS and Alzheimer disease [22, $48,54-56,66]$. However, in MS, as recently reported by Moore et al. [48], deposition of C9neo is observed predominantly in stromal concretions and at the subepithelial basement membrane, with only infrequent staining on choroid epithelial cells. Our study corroborates this finding: in Fig. 9j, we show that C9neo is almost entirely restricted to subepithelial basement membrane and stromal concretions in MS tissue. What sets NMO apart from the normal, non-pathogenic deposition of complement within the choroid stroma is the presence of AQP4 on the basolateral head). C9neo deposition is present in stromal concretions ( $\mathbf{j}$; arrow$h e a d)$ and in the perivascular basement membrane (j inset; arrow) but not on choroid epithelial cell membranes. Diffuse IgG immunoreactivity is observed in the choroid plexus $(\mathbf{k})$, predominantly restricted to the stroma and perivascular region $(\mathbf{I}$; arrow; inset). Scale bars in $\mathbf{a}-\mathbf{d}, \mathbf{f}, \mathbf{g}-\mathbf{j}$, and $\mathbf{l}=50 \mu \mathrm{m}$. Scale bars in $\mathbf{e}$ and $\mathbf{k}=100 \mu \mathrm{m}$. Immunohistochemistry for AQP4 (b, h); KiM1P (c, i); C9neo (d, j); and IgG $(\mathbf{e}, \mathbf{f}, \mathbf{k}, \mathbf{l})$

membrane of the epithelial cells adjacent to the basement membrane and stroma. Rather than accumulate in concretions, some of the circulating NMO IgG that crosses into the choroid stroma may find antigenic target and trigger complement deposition on the epithelial cell membranes. This is supported by the staining in Fig. 9d, in which C9neo is clearly present on the epithelial cell membrane. Thus, while immunoglobulin and complement deposition in the choroid plexus are not unique to NMO, per se, the distribution of these factors beyond the stroma and basement membrane is uniquely driven by the availability of the AQP4 target antigen and the presence of anti-AQP4 antibody in NMO patients.

The presence of C9neo on choroid epithelial cells raises the possibility of complement-mediated damage to the 
choroid as a pathogenic trigger in NMO. However, paradoxically, while we observed ependymal disorganization and discontinuity coincident with C9neo deposition and subpial vacuolations associated with $\mathrm{C} 9$ neo deposition at the pial glia limitans, we did not find evidence for overt choroid plexus damage. In this context, it is noteworthy that AQP4 is also expressed on the basolateral membrane of kidney epithelial cells in the distal tubule [72] and is accessible to NMO IgG across the peritubular capillary endothelial cells in the same manner that it is accessible in the choroid plexus [36]. However, kidney pathology has not been widely reported in NMO patients, with only two studies suggesting possible injury to AQP4-expressing tubular epithelial cells, both of which occurred in unusual circumstances [25, 49]. This may be explained by the robust expression of complement regulatory factors on the basolateral membrane of distal tubule and collecting duct cells in the kidney [63]. Choroid plexus epithelial cells also express complement regulatory proteins and upregulate expression of factors, such as CD46 and CD59 under pathogenic conditions [5, 68]. Moreover, several studies indicate that $\mathrm{C} 9$ neo deposition, despite being equated with obligate lytic destruction in much of the literature, can be detected in the absence of damage due to regulation of the terminal membrane attack complex by molecules, such as vitronectin and clusterin [7,21]. The expression of these molecules in the human choroid plexus is currently unknown, but the maintenance of physical integrity at the blood-CSF barrier despite heightened C9neo deposition suggests that something is preventing lytic destruction. Likewise, while we speculate that the blood-CSF barrier may serve as a unique entry point for NMO IgG into the CNS, it is not clear whether such transmission requires a physical compromise of the barrier or whether changes in AQP4 expression, microglial activation, and complement cascade engagement initiate a functional compromise or modulation that permits IgG introduction from the blood into the CSF.

If circulating NMO IgG enters the CSF at the choroid plexus, it may initiate a cascade of events that eventually leads to parenchymal astrocyte injury and subsequent secondary loss of myelin [39]. Our observation of AQP4 expression on the basolateral surface of ependymal cells in normal tissue and the loss of ependymal AQP4 expression in NMO tissue, as well as evidence of ependymal discontinuity and C9neo deposition on ependymal cells, suggests that CSF NMO IgG gained access to this CSF-brain barrier and elicited damage. Likewise, astrocyte reactivity, loss of AQP4 expression, and deposition of C9neo at the pial glia limitans, associated with subpial vacuolated tissue, suggest that this CSF-brain barrier was also targeted by NMO IgG. While ependymal cells along the ventricle are connected by intermediate junctions [51] and pial fibroblasts are joined by desmosomes [18], neither of these structures are as restrictive to IgG diffusion as tight junctions [44]. At these sites, NMO IgG would have access to AQP4 expressed on the basolateral surface of ependymal cells as well as to AQP4 expressed on astrocytic endfeet. Thus, serum NMO IgG may gain access to brain parenchyma by transitioning through the blood-CSF barrier at the choroid plexus, circulating through the CSF, and then transitioning through the CSF-brain barriers at the ependyma and the pial glia limitans. Ultimately, this blood-to-CSF-to-brain transition of NMO IgG may result in an inside-out antibody-mediated compromise of the blood-brain barrier, providing direct access of NMO IgG from blood-to-brain. In addition, the CSF route for NMO IgG entry into the brain parenchyma could generate reactive astrocyte responses that drive granulocytic infiltration even across an intact blood-brain barrier [23, 77], inducing inflammatory-mediated, leukocytedependent pathology within the parenchyma [40].

Our findings, therefore, suggest a possible pathogenic role for NMO IgG in the CSF. NMO IgG is detected in CSF and levels are predicted by recent relapse and high serum NMO IgG titer [26, 43]. Increased total CSF protein and elevated CSF lactate and albumin levels also correlate with NMO disease severity and acute relapse, suggesting a relationship between dysfunction at the blood-CSF barrier and disability $[26,31,82]$. Conversely, in a study of ten NMO patients with CSF NMO IgG measured at relapse, follow-up measurements after treatment revealed that a reduction in NMO IgG in CSF correlated with clinical improvement, though serum levels were not correlated with remission [11]. The concept of distinct pathogenic roles for CSF and serum NMO IgG is further supported by evidence that plasmapheresis showed delayed efficacy in some NMO patients, suggesting that the initial washout was insufficient to improve function $[30,38]$. Together, these findings support the CSF compartment as an important source of pathogenic NMO IgG. The cascades elicited by CSF NMO IgG likely include the direct induction of complement-mediated injury to CSF-brain interfaces and parenchymal astrocytes, as well as the initiation of self-amplifying astrocytic stress responses, as discussed above. However, an equally important mechanism of injury triggered by NMO IgG in the CSF may be disruption of normal water homeostasis at the blood-CSF and CSF-brain barriers.

Pathologic changes in brain water content manifest in two distinct but inter-related ways: edema, associated with increased water in the brain parenchyma [71], and hydrocephalus, associated with increased water in the CSF [8]. Edema is generally categorized as cytotoxic, in which reduced water transport function in parenchymal cells leads to interstitial shrinkage and intracellular swelling in the absence of blood-brain disruption, or vasogenic, in which blood-brain barrier damage induces interstitial 
accumulation of water. Brain edema is cleared by interstitial or cellular water flow across the glia limitans superficialis into CSF and then into the blood, by water flow across the ependyma into the CSF and then into the blood, and by flow across the glia limitans perivascularis directly into the blood [70]. AQP4 is clearly involved in edema [71], such that genetic deletion of AQP4 results in reduced cytotoxic edema by limiting the rate of water accumulation in the parenchyma, but increased vasogenic edema by reducing water clearance at the CSF-brain and blood-CSF barriers [62]. In NMO, this suggests that loss of AQP4-expressing cells or loss of AQP4 expression at the CSF-brain barrier in the ependyma or pial glia limitans will reduce the capacity to remove water from the parenchyma, facilitating edema. Indeed, evidence of extensive T2-weighted MRI hyperintensities in subcortical white matter coupled to an absence of gadolinium enhancement by T1 MRI and an increase in the apparent diffusion coefficient indicates the presence of pseudo-vasogenic interstitial edema in NMO [64]. Similar observations of increased apparent diffusion coefficient in normal-appearing white matter in the absence of gadolinium enhancement [27] further argue for a pseudovasogenic edema in NMO in which interstitial water is increased without blood-brain barrier dysfunction due to failure to transport water at CSF-brain interfaces [12]. This model is consistent with the loss of AQP4 expression and vacuolated underlying tissue observed at these barrier sites in NMO, and with our previous report of intramyelinic edema [20]. This model also highlights the role of AQP4 loss at CSF-brain interfaces in the transient edema we previously described in NMO patients with posterior reversible encephalopathy syndrome [42].

We recently reported that obstructive hydrocephalus is found in NMO patients at a higher frequency than observed in the general adult population [6]. On the basis of these cases, we predicted a primary involvement of ependyma in NMO and our current findings support this concept. However, the pathogenic mechanisms underlying hydrocephalus in NMO are not straightforward. While evidence from mice lacking AQP4 expression indicates about a $10 \%$ incidence of hydrocephalus triggered by complete obstruction of the cerebral aqueduct [14], it is not clear why such obstructions occur. AQP4-null mice exhibit an intact blood-brain barrier but a disorganized ependymal cell layer, even in animals without hydrocephalus [14], supporting a model in which loss of AQP4, whether genetic or antibody-mediated, induces defects in CSF homeostasis. However, loss of AQP4 at the blood-CSF barrier in the choroid plexus may have counteracting effects on CSF production, resulting in little change in overall CSF volume. This model argues against CSF hyper-production as the cause of hydrocephalus in NMO, though it remains possible that hypo-production of CSF due to loss of choroid plexus epithelial cells could impact ventricular flow in a manner that increases the likelihood of aqueductal blockage. Such blockage and subsequent obstructive hydrocephalus may also arise as a result of ependymal cell loss induced by the NMO IgGmediated complement deposition we observed in this study. Humans and mice with primary ciliary dyskinesia exhibit hydrocephalus [32], and genetic deletion or mutation of multiple specific ciliary proteins results in ependymal cilia beat defects and consequent hydrocephalus induced by reduced CSF flow [15, 33, 45, 79]. Additional evidence indicates that laminar CSF propulsion mediated by ependymal cilia is required to maintain aqueductal patency, and defects in such propulsion result in aqueduct stenosis and triventricular hydrocephalus [24]. Ultimately, short of catastrophic loss of ependymal cells and/or choroid plexus epithelial cells or the initiation of an amplification loop that results in a rapid rise in intracerebral pressure and consequent collapse of the aqueduct, it is likely that overt hydrocephalus in NMO is at one end of a spectrum that more frequently manifests as transient pressure increases and disorganized CSF flow. Regardless, these events may contribute to pathologic events in the brain parenchyma that run in parallel to direct NMO IgG-induced astrocyte pathology. Indeed, it is possible that preventing damage at the bloodCSF and CSF-brain interfaces may substantially reduce or delay direct parenchymal damage by the NMO IgG. In light of this, it is noteworthy that we observed robust complement deposition at the choroid plexus and ependymal interfaces, suggesting that these sites may be directly protected by complement cascade blocking therapies, such as eculizumab [57]. It would be of interest in future studies to determine if eculizumab therapy alters the imaging hallmarks of pseudo-vasogenic edema in NMO patients as a secondary outcome measure.

The pathology findings we describe also provide mechanistic evidence for our previous report of periependymal and periventricular MRI abnormalities [58]. These included fluid-attenuated inversion recovery (FLAIR) and T2 signal abnormalities in periependymal regions of the lateral ventricles and along the walls of the third and fourth ventricles and the aqueduct of Sylvius. In meningitis, FLAIR hyperintensity is caused by elevated CSF protein content related to leptomeningeal inflammation [29], which extends the effective echo time beyond the inversion time used to suppress bulk CSF [47]. This same effect results in T2 hyperintensity. Therefore, our previously reported MRI findings are consistent with pathological changes at the ependymal CSF-brain and choroid plexus blood-CSF barriers that may involve both inflammation (Fig. 6k, 1) and decreased local CSF flow due to cell injury or loss and barrier breach (Fig. 6i, j). Likewise, the reports of the so-called "pencil thin" ependymal hyperintensities with contrastenhanced FLAIR imaging [2] support a dynamic alteration 
or disruption at the CSF-brain barrier. Notably, in common with infection-induced changes in the ependyma and choroid plexus [16], intraventricular exudate ("ventricular debris") may be an expected MRI observation during acute attacks in NMO patients and may contribute to a loss of aqueduct patency that triggers hydrocephalus [60].

In conclusion, we provide evidence that the interfaces between blood and CSF and between CSF and brain are key sites for the initiation of NMO pathophysiology. Furthermore, the pathology at these sites may have important implications for disease evolution in NMO patients, including serving as the possible point at which serum NMO IgG enters the CNS and gains broad access to the brain parenchyma. Our findings also indicate that NMO is an "AQP4opathy" with pathological targets beyond the astrocyte and provide insight into recent reports of edema [12, 20, 27, 42, 64] and hydrocephalus [6] in NMO patients that may suggest a unique model for CSF flow-dependent pathogenic events in this disease. Finally, the abundance of complement activation products in the choroid plexus, pial glia limitans, and ependymal layer suggests that these sites may be key targets for complement blocking therapies [57]. As such, imaging of these interfaces and other measures of CSF homeostasis may offer quantifiable tests of efficacy in future trials using therapies that target the complement pathway in NMO.

Acknowledgements The authors thank Patricia Ziemer, Mayo Clinic, for technical assistance. This work was supported by funding from the Guthy-Jackson Charitable Foundation.

Open Access This article is distributed under the terms of the Creative Commons Attribution 4.0 International License (http://creativecommons.org/licenses/by/4.0/), which permits unrestricted use, distribution, and reproduction in any medium, provided you give appropriate credit to the original author(s) and the source, provide a link to the Creative Commons license, and indicate if changes were made.

\section{References}

1. Amiry-Moghaddam M, Ottersen OP (2003) The molecular basis of water transport in the brain. Nat Rev Neurosci 4:991-1001

2. Banker P, Sonni S, Kister I, Loh JP, Lui YW (2012) Pencil-thin ependymal enhancement in neuromyelitis optica spectrum disorders. Mult Scler 18:1050-1053

3. Boyer RS, Sun NC, Verity A, Nies KM, Louie JS (1980) Immunoperoxidase staining of the choroid plexus in systemic lupus erythematosus. J Rheumatol 7:645-650

4. Brentjens J, Ossi E, Albini B, Sepulveda M, Kano K, Sheffer J, Vasilion P, Marine E, Baliah T, Jockin H et al (1977) Disseminated immune deposits in lupus erythematosus. Arthritis Rheum 20:962-968

5. Canova C, Neal JW, Gasque P (2006) Expression of innate immune complement regulators on brain epithelial cells during human bacterial meningitis. J Neuroinflammation 3:22
6. Clardy SL, Lucchinetti CF, Krecke KN, Lennon VA, O'Toole O, Weinshenker BG, Boyd CD, Krieger S, McGraw C, Guo Y et al (2014) Hydrocephalus in neuromyelitis optica. Neurology 82:1841-1843

7. Dahlback K, Lofberg H, Dahlback B (1989) Vitronectin colocalizes with Ig deposits and C9 neoantigen in discoid lupus erythematosus and dermatitis herpetiformis, but not in bullous pemphigoid. Br J Dermatol 120:725-733

8. Damkier HH, Brown PD, Praetorius J (2013) Cerebrospinal fluid secretion by the choroid plexus. Physiol Rev 93:1847-1892

9. Davis JA, Weisman MH, Dail DH (1978) Vascular disease in infective endocarditis. Report of immune-mediated events in skin and brain. Arch Intern Med 138:480-483

10. Derouiche A, Pannicke T, Haseleu J, Blaess S, Grosche J, Reichenbach A (2012) Beyond polarity: functional membrane domains in astrocytes and Muller cells. Neurochem Res 37:2513-2523

11. Dujmovic I, Mader S, Schanda K, Deisenhammer F, Stojsavljevic N, Kostic J, Berger T, Drulovic J, Reindl M (2011) Temporal dynamics of cerebrospinal fluid anti-aquaporin- 4 antibodies in patients with neuromyelitis optica spectrum disorders. J Neuroimmunol 234:124-130

12. Eichel R, Meiner Z, Abramsky O, Gotkine M (2008) Acute disseminating encephalomyelitis in neuromyelitis optica: closing the floodgates. Arch Neurol 65:267-271

13. Falangola MF, Castro-Filho BG, Petito CK (1994) Immune complex deposition in the choroid plexus of patients with acquired immunodeficiency syndrome. Ann Neurol 36:437-440

14. Feng X, Papadopoulos MC, Liu J, Li L, Zhang D, Zhang H, Verkman AS, Ma T (2009) Sporadic obstructive hydrocephalus in Aqp4 null mice. J Neurosci Res 87:1150-1155

15. Finn R, Evans CC, Lee L (2014) Strain-dependent brain defects in mouse models of primary ciliary dyskinesia with mutations in Pcdp1 and Spef2. Neuroscience 277:552-567

16. Fukui MB, Williams RL, Mudigonda S (2001) CT and MR imaging features of pyogenic ventriculitis. AJNR Am J Neuroradiol 22:1510-1516

17. Gershwin ME, Hyman LR, Steinberg AD (1975) The choroid plexus in CNS involvement of systemic lupus erythematosus. J Pediatr 87:588-590

18. Getsios S, Huen AC, Green KJ (2004) Working out the strength and flexibility of desmosomes. Nat Rev Mol Cell Biol 5:271-281

19. Guo Y, Lennon VA, Popescu BF, Grouse CK, Topel J, Milone M, Lassmann H, Parisi JE, Pittock SJ, Stefoski D et al (2014) Autoimmune aquaporin-4 myopathy in neuromyelitis optica spectrum. JAMA Neurol 71:1025-1029

20. Hinson SR, Romero MF, Popescu BF, Lucchinetti CF, Fryer JP, Wolburg H, Fallier-Becker P, Noell S, Lennon VA (2012) Molecular outcomes of neuromyelitis optica (NMO)-IgG binding to aquaporin-4 in astrocytes. Proc Natl Acad Sci USA 109:1245-1250

21. Hintner H, Sepp N, Dahlback K, Dahlback B, Fritsch P, Breathnach SM (1990) Deposition of C3, C9 neoantigen and vitronectin (S-protein of complement) in lichen planus pemphigoides. Br J Dermatol 123:39-47

22. Hoffman WH, Casanova MF, Cudrici CD, Zakranskaia E, Venugopalan R, Nag S, Oglesbee MJ, Rus H (2007) Neuroinflammatory response of the choroid plexus epithelium in fatal diabetic ketoacidosis. Exp Mol Pathol 83:65-72

23. Howe CL, Kaptzan T, Magana SM, Ayers-Ringler JR, LaFranceCorey RG, Lucchinetti CF (2014) Neuromyelitis optica IgG stimulates an immunological response in rat astrocyte cultures. Glia 62:692-708

24. Ibanez-Tallon I, Pagenstecher A, Fliegauf M, Olbrich H, Kispert A, Ketelsen UP, North A, Heintz N, Omran H (2004) 
Dysfunction of axonemal dynein heavy chain Mdnah5 inhibits ependymal flow and reveals a novel mechanism for hydrocephalus formation. Hum Mol Genet 13:2133-2141

25. Iorio R, Monforte M, Pierconti F, Iodice F, Sabatelli M (2014) Tuberculous nephritis accompanying neuromyelitis optica: causal or coincidental association? J Neurol 261:1028-1030

26. Jarius S, Franciotta D, Paul F, Ruprecht K, Bergamaschi R, Rommer PS, Reuss R, Probst C, Kristoferitsch W, Wandinger $\mathrm{KP}$ et al (2010) Cerebrospinal fluid antibodies to aquaporin-4 in neuromyelitis optica and related disorders: frequency, origin, and diagnostic relevance. J Neuroinflammation 7:52

27. Jeantroux J, Kremer S, Lin XZ, Collongues N, Chanson JB, Bourre B, Fleury M, Blanc F, Dietemann JL, de Seze J (2012) Diffusion tensor imaging of normal-appearing white matter in neuromyelitis optica. J Neuroradiol 39:295-300

28. Johanson CE, Stopa EG, McMillan PN (2011) The blood-cerebrospinal fluid barrier: structure and functional significance. Methods Mol Biol 686:101-131

29. Kamran S, Bener AB, Alper D, Bakshi R (2004) Role of fluidattenuated inversion recovery in the diagnosis of meningitis: comparison with contrast-enhanced magnetic resonance imaging. J Comput Assist Tomogr 28:68-72

30. Kim SH, Kim W, Huh SY, Lee KY, Jung IJ, Kim HJ (2013) Clinical efficacy of plasmapheresis in patients with neuromyelitis optica spectrum disorder and effects on circulating antiaquaporin-4 antibody levels. J Clin Neurol 9:36-42

31. Kim SM, Waters P, Vincent A, Go MJ, Park KS, Sung JJ, Lee KW (2011) Cerebrospinal fluid/serum gradient of IgG is associated with disability at acute attacks of neuromyelitis optica. J Neurol 258:2176-2180

32. Lee L (2013) Riding the wave of ependymal cilia: genetic susceptibility to hydrocephalus in primary ciliary dyskinesia. $\mathbf{J}$ Neurosci Res 91:1117-1132

33. Lee L, Campagna DR, Pinkus JL, Mulhern H, Wyatt TA, Sisson JH, Pavlik JA, Pinkus GS, Fleming MD (2008) Primary ciliary dyskinesia in mice lacking the novel ciliary protein Pcdp1. Mol Cell Biol 28:949-957

34. Lennon VA, Kryzer TJ, Pittock SJ, Verkman AS, Hinson SR (2005) IgG marker of optic-spinal multiple sclerosis binds to the aquaporin-4 water channel. J Exp Med 202:473-477

35. Lennon VA, Wingerchuk DM, Kryzer TJ, Pittock SJ, Lucchinetti CF, Fujihara K, Nakashima I, Weinshenker BG (2004) A serum autoantibody marker of neuromyelitis optica: distinction from multiple sclerosis. Lancet 364:2106-2112

36. Li Z, Terada N, Ohno N, Ohno S (2005) Immunohistochemical analyses on albumin and immunoglobulin in acute hypertensive mouse kidneys by "in vivo cryotechnique". Histol Histopathol 20:807-816

37. Liddelow SA (2015) Development of the choroid plexus and blood-CSF barrier. Front Neurosci 9:32

38. Llufriu S, Castillo J, Blanco Y, Ramio-Torrenta L, Rio J, Valles M, Lozano M, Castella MD, Calabia J, Horga A et al (2009) Plasma exchange for acute attacks of CNS demyelination: predictors of improvement at 6 months. Neurology 73:949-953

39. Lucchinetti CF, Guo Y, Popescu BF, Fujihara K, Itoyama Y, Misu $\mathrm{T}$ (2014) The pathology of an autoimmune astrocytopathy: lessons learned from neuromyelitis optica. Brain Pathol 24:83-97

40. Lucchinetti CF, Mandler RN, McGavern D, Bruck W, Gleich G, Ransohoff RM, Trebst C, Weinshenker B, Wingerchuk D, Parisi JE et al (2002) A role for humoral mechanisms in the pathogenesis of Devic's neuromyelitis optica. Brain 125:1450-1461

41. Magana SM, Keegan BM, Weinshenker BG, Erickson BJ, Pittock SJ, Lennon VA, Rodriguez M, Thomsen K, Weigand S, Mandrekar J et al (2011) Beneficial plasma exchange response in central nervous system inflammatory demyelination. Arch Neurol 68:870-878
42. Magana SM, Matiello M, Pittock SJ, McKeon A, Lennon VA, Rabinstein AA, Shuster E, Kantarci OH, Lucchinetti CF, Weinshenker BG (2009) Posterior reversible encephalopathy syndrome in neuromyelitis optica spectrum disorders. Neurology 72:712-717

43. Majed M, Fryer JP, McKeon A, Lennon VA, Pittock SJ (2016) Clinical utility of testing AQP4-IgG in CSF: guidance for physicians. Neurol Neuroimmunol Neuroinflamm 3:e231

44. Marchiando AM, Graham WV, Turner JR (2010) Epithelial barriers in homeostasis and disease. Annu Rev Pathol 5:119-144

45. Matsuo M, Shimada A, Koshida S, Saga Y, Takeda H (2013) The establishment of rotational polarity in the airway and ependymal cilia: analysis with a novel cilium motility mutant mouse. Am J Physiol Lung Cell Mol Physiol 304:L736-L745

46. McIntosh RM, Copack P, Chernack WB, Griswold WR, Weil R 3rd, Koss MN (1975) The human choroid plexus and autoimmune nephritis. Arch Pathol 99:48-50

47. Melhem ER, Jara H, Eustace S (1997) Fluid-attenuated inversion recovery MR imaging: identification of protein concentration thresholds for CSF hyperintensity. AJR Am J Roentgenol 169:859-862

48. Moore GR, Laule C, Leung E, Pavlova V, Morgan BP, Esiri MM (2016) Complement and humoral adaptive immunity in the human choroid plexus: roles for stromal concretions, basement membranes, and epithelium. J Neuropathol Exp Neurol $75: 415-428$

49. Mottaghi P, Ashtari F, Karimzadeh H, Seidbonakdar Z, Karimifar M, Salesi M (2009) Devic's syndrome concomitant with nephritis in a young woman. Clin Rheumatol 28:1239-1240

50. Neely JD, Amiry-Moghaddam M, Ottersen OP, Froehner SC, Agre P, Adams ME (2001) Syntrophin-dependent expression and localization of aquaporin-4 water channel protein. Proc Natl Acad Sci USA 98:14108-14113

51. Oliver C, Gonzalez CA, Alvial G, Flores CA, Rodriguez EM, Batiz LF (2013) Disruption of CDH2/N-cadherin-based adherens junctions leads to apoptosis of ependymal cells and denudation of brain ventricular walls. J Neuropathol Exp Neurol 72:846-860

52. Olsson JE, Link H (1973) Distribution of serum proteins and beta-trace protein within the nervous system. J Neurochem 20:837-846

53. Papadopoulos MC, Verkman AS (2013) Aquaporin water channels in the nervous system. Nat Rev Neurosci 14:265-277

54. Pittella JE, Bambirra EA (1989) Histopathological and immunofluorescence study of the choroid plexus in hepatosplenic schistosomiasis mansoni. Am J Trop Med Hyg 41:548-552

55. Pittella JE, Bambirra EA (1991) Immune complexes in the choroid plexus in liver cirrhosis. Arch Pathol Lab Med 115:220-222

56. Pittella JE, Bambirra EA (1988) Immune complexes in the choroid plexus in systemic hypertension. J Clin Pathol 41:1245-1246

57. Pittock SJ, Lennon VA, McKeon A, Mandrekar J, Weinshenker BG, Lucchinetti CF, O'Toole O, Wingerchuk DM (2013) Eculizumab in AQP4-IgG-positive relapsing neuromyelitis optica spectrum disorders: an open-label pilot study. Lancet Neurol 12:554-562

58. Pittock SJ, Weinshenker BG, Lucchinetti CF, Wingerchuk DM, Corboy JR, Lennon VA (2006) Neuromyelitis optica brain lesions localized at sites of high aquaporin 4 expression. Arch Neurol 63:964-968

59. Popescu BF, Lennon VA, Parisi JE, Howe CL, Weigand SD, Cabrera-Gomez JA, Newell K, Mandler RN, Pittock SJ, Weinshenker BG et al (2011) Neuromyelitis optica unique area postrema lesions: nausea, vomiting, and pathogenic implications. Neurology 76:1229-1237 
60. Rappaport ZH, Shalit MN (1989) Perioperative external ventricular drainage in obstructive hydrocephalus secondary to infratentorial brain tumours. Acta Neurochir (Wien) 96:118-121

61. Roemer SF, Parisi JE, Lennon VA, Benarroch EE, Lassmann H, Bruck W, Mandler RN, Weinshenker BG, Pittock SJ, Wingerchuk DM et al (2007) Pattern-specific loss of aquaporin-4 immunoreactivity distinguishes neuromyelitis optica from multiple sclerosis. Brain 130:1194-1205

62. Saadoun S, Papadopoulos MC (2010) Aquaporin-4 in brain and spinal cord oedema. Neuroscience 168:1036-1046

63. Saadoun S, Papadopoulos MC (2015) Role of membrane complement regulators in neuromyelitis optica. Mult Scler 21:1644-1654

64. Saiki S, Ueno Y, Moritani T, Sato T, Sekine T, Kawajiri S, Adachi S, Yokoyama K, Tomizawa Y, Motoi Y et al (2009) Extensive hemispheric lesions with radiological evidence of blood-brain barrier integrity in a patient with neuromyelitis optica. J Neurol Sci 284:217-219

65. Saji E, Arakawa M, Yanagawa K, Toyoshima Y, Yokoseki A, Okamoto K, Otsuki M, Akazawa K, Kakita A, Takahashi H et al (2013) Cognitive impairment and cortical degeneration in neuromyelitis optica. Ann Neurol 73:65-76

66. Serot JM, Bene MC, Faure GC (1994) Comparative immunohistochemical characteristics of human choroid plexus in vascular and Alzheimer's dementia. Hum Pathol 25:1185-1190

67. Sher JH, Pertschuk LP (1974) Immunoglobulin G deposits in the choroid plexus of a child with systemic lupus erythematosus. J Pediatr 85:385-387

68. Singhrao SK, Neal JW, Rushmere NK, Morgan BP, Gasque P (1999) Differential expression of individual complement regulators in the brain and choroid plexus. Lab Invest 79:1247-1259

69. Sofroniew MV (2015) Astrocyte barriers to neurotoxic inflammation. Nat Rev Neurosci 16:249-263

70. Stokum JA, Gerzanich V, Simard JM (2015) Molecular pathophysiology of cerebral edema. J Cereb Blood Flow Metab 36(3):513-538

71. Stokum JA, Kurland DB, Gerzanich V, Simard JM (2015) Mechanisms of astrocyte-mediated cerebral edema. Neurochem Res 40:317-328
72. Terris J, Ecelbarger CA, Marples D, Knepper MA, Nielsen S (1995) Distribution of aquaporin-4 water channel expression within rat kidney. Am J Physiol 269:F775-F785

73. Tham DK, Moukhles H (2011) Regulation of Kir4.1 and AQP4 expression and stability at the basolateral domain of epithelial MDCK cells by the extracellular matrix. Am J Physiol Renal Physiol 301:F396-F409

74. Tietz S, Engelhardt B (2015) Brain barriers: crosstalk between complex tight junctions and adherens junctions. J Cell Biol 209:493-506

75. Vella J, Zammit C, Di Giovanni G, Muscat R, Valentino M (2015) The central role of aquaporins in the pathophysiology of ischemic stroke. Front Cell Neurosci 9:108

76. Verkman AS, Phuan PW, Asavapanumas N, Tradtrantip L (2013) Biology of AQP4 and anti-AQP4 antibody: therapeutic implications for NMO. Brain Pathol 23:684-695

77. Walker-Caulfield ME, Guo Y, Johnson RK, McCarthy CB, FitzGibbon PD, Lucchinetti CF, Howe CL (2015) NFkappaB signaling drives pro-granulocytic astroglial responses to neuromyelitis optica patient IgG. J Neuroinflammation 12:185

78. Whish S, Dziegielewska KM, Mollgard K, Noor NM, Liddelow SA, Habgood MD, Richardson SJ, Saunders NR (2015) The inner CSF-brain barrier: developmentally controlled access to the brain via intercellular junctions. Front Neurosci 9:16

79. Wilson GR, Wang HX, Egan GF, Robinson PJ, Delatycki MB, O'Bryan MK, Lockhart PJ (2010) Deletion of the Parkin coregulated gene causes defects in ependymal ciliary motility and hydrocephalus in the quakingviable mutant mouse. Hum Mol Genet 19:1593-1602

80. Wingerchuk DM, Lennon VA, Lucchinetti CF, Pittock SJ, Weinshenker BG (2007) The spectrum of neuromyelitis optica. Lancet Neurol 6:805-815

81. Woodroffe AJ (1981) IgA, glomerulonephritis and liver disease. Aust N Z J Med 11:109-111

82. Zaffaroni M, Italian Devic's Study G (2004) Cerebrospinal fluid findings in Devic's neuromyelitis optica. Neurol Sci 25(Suppl 4):S368-S370 